\title{
Trichuris spp. infecting domestic cats on St. Kitts: identification based on size or vulvar structure?
}

\author{
Jennifer K Ketzis
}

\begin{abstract}
Background: On St. Kitts, a high number of cats are found to be infected with Trichuris. Necropsies have shown pathologic changes related to the infections. In order to determine if these changes were related to a particular Trichuris species, a review of the original identifications of Trichuris campanula and Trichuris serrata was conducted.

Findings: Based on the review of published descriptions of T. campanula and T. serrata, it is hypothesized that the presence or absence of a vulvar projection and a bacillary band can be used to differentiate the two species and these criteria are more accurate than nematode or egg size. The Trichuris in cats on St. Kitts were similar in size to the description of T. campanula, but had both a vulvar projection and bacillary band.

Conclusions: Based on the morphological characteristics, all of the Trichuris found in twelve domestic cats were determined to be T. serrata. Cats without pathologic changes are required to further investigate if the changes are species or strain related.
\end{abstract}

Keywords: Cats; Trichuris spp; Trichuris serrata; Trichuris campanula

\section{Introduction}

Two species of Trichuris in domestic cats, Trichuris serrata and Trichuris campanula, were originally described by von Linstow 1879,1889 , respectively. The number of worms used in these original descriptions, isolated from cats in Brazil, was limited and no whole male was available for T. campanula. In 1923, Urioste described specimens from Brazil and asserted that there was only one species infecting cats, $T$. serrata (Cameron 1937; Clarkson and Owen 1960). However, his description was later combined with von Linstow's original description of $T$. campanula to provide a more complete description of the species (Clarkson and Owen 1960; Ng and Kelly 1975). Descriptions of the two species were expanded by Cameron (1937), Clarkson and Owen (1960), Kelly (1973) and Ng and Kelly (1975). Neither of these species has been described using molecular methods.

There is some debate regarding if there really are two species of Trichuris in cats or just one species (Bowman et al. 2002). However, according to the original descriptions by von Linstow (1879 and 1889), a description of T. serrata by Cameron (1937) and descriptions of both

Correspondence: jketzis@rossvet.edu.kn

Department of Biomedical Sciences, Ross University School of Veterinary Medicine, PO Box 334, Basseterre, St. Kitts and Nevis, West Indies species by Kelly (1973) and Ng and Kelly (1975), the distinguishing characteristic between the species is the presence of a finger-like projection on the vulva of $T$. serrata versus two inconspicuous longitudinal lips on the vulva of $T$. campanula. In addition, $\mathrm{Ng}$ and Kelly (1975) used the absence of a bacillary band in T. campanula to distinguish it from $T$. serrata. The eggs, in all of these identifications, have been described as typical Trichuroid (light brown, lemon shaped with biopolar plugs and a morula) with no particular distinguishing morphological characteristics.

In other identifications, size of the adult worms and the eggs have been used to distinguish the two species, with $T$. campanula adult worms being slightly smaller and the eggs being slightly larger than those of $T$. serrata. When Clarkson and Owen (1959) first described Trichuris from cats in the Bahamas, they described the size as that of $T$. campanula and the finger-like projection as that of $T$. serrata. An archived specimen of $T$. campanula was obtained from Dr. G. Hatwich of the Zoological Museum in Berlin (no T. serrata specimens were available) to assist Clarkson and Owen (1960) in their identification. The archived specimen also had the finger-like projection, and therefore, the Bahaman species was considered T. campanula. Based on this, both 
Table 1 Morphological descriptions of Trichuris campanula and Trichuris serrata

\begin{tabular}{|c|c|c|c|c|c|c|c|}
\hline & \multicolumn{3}{|l|}{ T. campanula } & \multicolumn{3}{|l|}{ T. serrata } & \multirow[t]{2}{*}{ St. Kitts } \\
\hline & $\begin{array}{l}\text { von Linstow } \\
\text { (1889) }\end{array}$ & $\begin{array}{l}\mathrm{Ng} \text { and Kelly } \\
\text { (1975) }\end{array}$ & $\begin{array}{l}\text { Clarkson and } \\
\text { Owen (1960) }\end{array}$ & $\begin{array}{l}\text { von Linstow } \\
\text { (1879) }\end{array}$ & Kelly (1973) & Cameron (1937) & \\
\hline Female & 31.5 & 38 & 22.5 & 48 & 49.5 & 14.74 & 25 \\
\hline Length (mm) & $23.0^{*}$ & & & & & & $(14-31)$ \\
\hline Vulva & $\begin{array}{l}2 \text { not very } \\
\text { prominent lips }\end{array}$ & $\begin{array}{l}\text { Straight; } 2 \\
\text { inconspicuous } \\
\text { longitudinal lips }\end{array}$ & $\begin{array}{l}\text { Prominent spiny } \\
\text { structure directed } \\
\text { posteriorly }\end{array}$ & $\begin{array}{l}\text { Spiny structure } \\
\text { directed } \\
\text { posteriorly }\end{array}$ & $\begin{array}{l}\text { Appendage on } \\
\text { posterior lip } \\
\text { directed posteriorly }\end{array}$ & $\begin{array}{l}\text { Appendage on } \\
\text { posterior lip } \\
\text { directed posteriorly }\end{array}$ & $\begin{array}{l}\text { Appendage on } \\
\text { posterior lip } \\
\text { directed posteriorly }\end{array}$ \\
\hline \multirow[t]{2}{*}{ Eggs $(\mu \mathrm{m})$} & $72 \times 36$ & $81-85$ x 35-39 & $63 \times 34$ & $56 \times 39$ & $54 \times 40$ & $60 \times 35$ & \multirow{2}{*}{$\begin{array}{l}60-75 \times 30-40 \\
(38 \text { eggs })\end{array}$} \\
\hline & $80 \times 36^{*}$ & & & & & & \\
\hline Male & $20.5^{*}$ & 36 & 21.5 & 40 & 38 & 12.75 & $24(17-32)$ \\
\hline \multicolumn{8}{|l|}{ Length (mm) } \\
\hline Spicule & $1.5^{*}$ & 2.9 & 1.5 & 3.9 & 3.6 & 1.2 & 1.4 \\
\hline$(\mathrm{mm})$ & & & & & & & $(1.1-1.5)$ \\
\hline Other & - & No bacillary band & - & Bacillary band & Bacillary band & Bacillary band & Bacillary band \\
\hline \multirow[t]{2}{*}{ Source } & Domestic cat & Domestic cat & Domestic cat & Domestic cat & Domestic cat & Ocelot & Domestic cat \\
\hline & Brazil & Australia & Bahamas & Brazil & Australia & Trinidad & \\
\hline \multirow[t]{3}{*}{ Worms used } & 1 female & $<36$ total & 11 females & Unknown & 6 females & 3 females & 22 females \\
\hline & 1 partial male & & 6 males & & 13 males & 2 males & 12 males \\
\hline & Unknown ${ }^{*}$ & & & & & & 9 cats for eggs \\
\hline
\end{tabular}


T. campanula and T. serrata have the projection and size is the distinguishing characteristic. There was no mention regarding the presence or absence of bacillary bands in either of the specimens (that from the Bahamas or that from Berlin). Also, the measurements of the Berlin specimen are not included in the description by Clarkson and Owen (1960).

Since the identification by Clarkson and Owen (1960), feline Trichuris identification often has been based on egg or adult size, by referencing the description provided by Clarkson and Owen, and with no mention in regard to a vulvar projection or the bacillary band (Hass and Meisels 1978; Beldomenico et al. 2005). The exception to this is the identification by Kelly (1973) and $\mathrm{Ng}$ and Kelly (1975) who, as previously stated, relied on the presence or absence of the vulvar projection and the bacillary band for identification. A summary of the morphological characteristics of the two species are presented in Table 1.

On St. Kitts, an island in the West Indes, as many as $71 \%$ of feral cats and $22 \%$ of owned cats are infected with Trichuris (Krecek et al. 2010; Ketzis and Shell 2015). In necropsies performed on cats euthanized due to ill health (e.g., Feline immunodeficiency virus positive) or accidents (e.g., dog attack, hit by car), lesions related to Trichuris infections have been seen grossly in some of the cats and via histopathology in other cats. Some of the lesions are similar to those described by Kirkova and Dinev (2005) in Trichuris vulpis dog infections. Based on the literature, $T$. serrata and $T$. campanula occur in the Caribbean; therefore, either species could be the cause of the lesions seen on St. Kitts. Since species and strain differences in parasites can be related to their virulence and pathogenesis, this study was undertaken to determine the Trichuris species infecting cats on St. Kitts using the published morphological descriptions.

\section{Results and discussion}

The number of Trichuris recovered ranged from 1 to 117 with 96 male and 113 female adults collected (Table 2). All of the female worms had a finger-like projection on the vulva and all of the worms had a bacillary band (Figures $1 \mathrm{a}$ and $\mathrm{b}$ and $2 \mathrm{a}$ and $\mathrm{b}$ ). The length of the male worms (twelve measured) ranged from 17 to $32 \mathrm{~mm}$ and the female worms (twenty two measured) ranged from 14 to $31 \mathrm{~mm}$ (Table 1 ). The eggs ranged in size from $60-75 \times 30-40 \mu \mathrm{m}$ (38 measured; two to five per cat) and were typical Trichuroid (Figure $3 \mathrm{a}$ and $\mathrm{b}$ ).

Based on the presence of the finger-like projection and bacillary band, the Trichuris in cats on St. Kitts is T. serrata. However, if size is used for classification, then the parasite is more likely to be T. campanula. The eggs, on the other hand, are similar in size to both species with
Table 2 Trichuris from domestic cats on St. Kitts used for identification

\begin{tabular}{llllllll}
\hline Cat & \multicolumn{3}{l}{ Trichuris recovered } & & \multicolumn{3}{c}{ Trichuris for identification } \\
\cline { 2 - 3 } & Total & Males & Females & & Males & Females & Eggs \\
\hline 1 & 29 & 16 & 13 & 0 & 1 & - \\
2 & $6^{*}$ & 4 & 2 & 4 & 1 & 5 \\
3 & $5^{*}$ & 2 & 3 & 2 & 2 & 5 \\
4 & 4 & 3 & 1 & 2 & 0 & 2 \\
5 & $6^{*}$ & 3 & 3 & 3 & 3 & 3 \\
6 & 117 & 48 & 69 & 0 & 1 & 5 \\
7 & $7^{*}$ & 3 & 4 & 0 & 3 & 5 \\
8 & 21 & 15 & 6 & 0 & 4 & 5 \\
9 & 2 & 0 & 2 & 0 & 1 & - \\
10 & $5^{*}$ & 1 & 4 & 1 & 3 & 3 \\
11 & 1 & 0 & 1 & 0 & 1 & - \\
12 & 6 & 1 & 5 & 0 & 2 & 5 \\
Total & 209 & 96 & 113 & 12 & 22 & 38 \\
\hline
\end{tabular}

*Total does not include adult worms attached to intestinal sections submitted for pathology.

none of the eggs as large as some of the descriptions for T. campanula nor as small as some of the descriptions for $T$. serrata.

One of the difficulties in distinguishing the two species of Trichuris in cats is that few whole male and female worms were used in the original descriptions by von Linstow and there are only two researchers that have described both species: Kelly (1973) with eight male and six female adult worms identified as $T$. serrata and $\mathrm{Ng}$ and Kelly (1975) with an unspecified number of adult male and female worms identified as T. campanula; and Hass and Meisels (1978) with six adult worms from Florida identified as T. campanula and one non-intact male from Wisconsin identified as $T$. serrata. $\mathrm{Ng}$ and Kelly used the von Linstow (1879 and 1889) descriptions and Hass and Meisels (1978) used Clarkson and Owen (1960) as the reference for species identification.

Another difficulty in identification of the species is the description of $T$. campanula provided by Clarkson and Owen (1960). While this is the only description of $T$. campanula with a finger-like vulvar projection, this description was instrumental in distinguishing the parasites by size. The discrepancy created by Clarkson and Owen might be due to the projection not being seen in the originally identified $T$. campanula (i.e., both species have it), an omission in the first description of T. campanula since it was described after $T$. serrata or the archived specimen used might have been mislabeled. The drawings provided by Clarkson and Owen almost perfectly match those of Cameron's T. serrata and the description provided by von Linstow of $T$. serrata. 

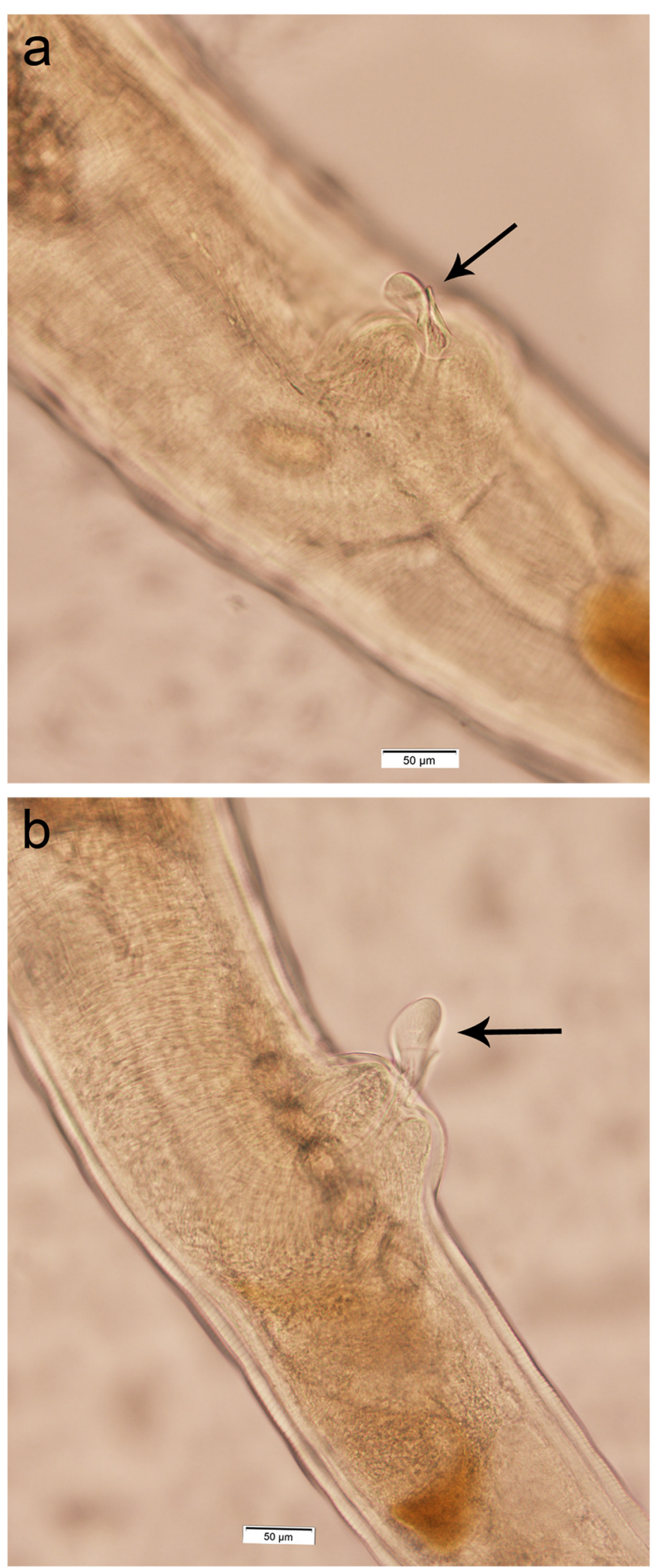

Figure $1 \mathrm{a}$ and b Vulvar projection (200x) of two female Trichuris from different St. Kitts' cats. 

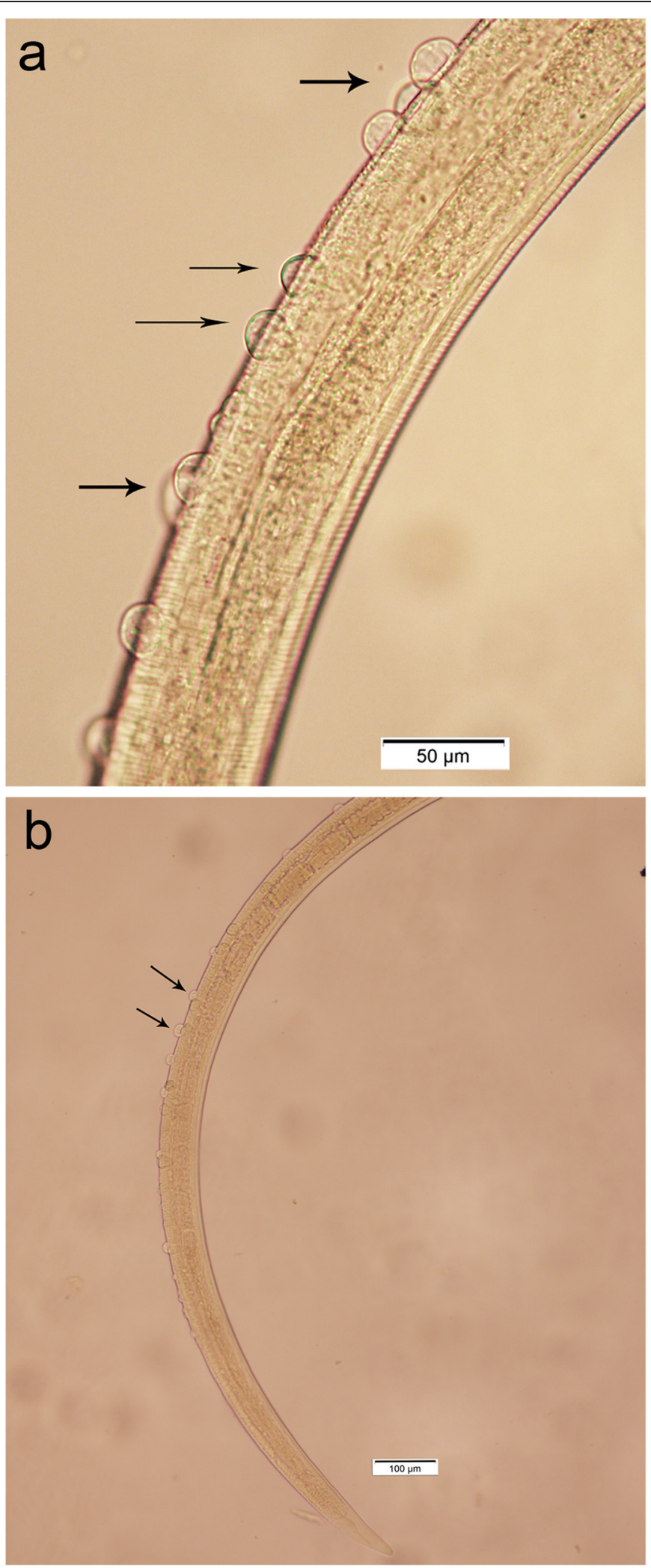

Figure 2 a and b Bacillary band (100x and 200x) of two female Trichuris from different St. Kitts' cats. 

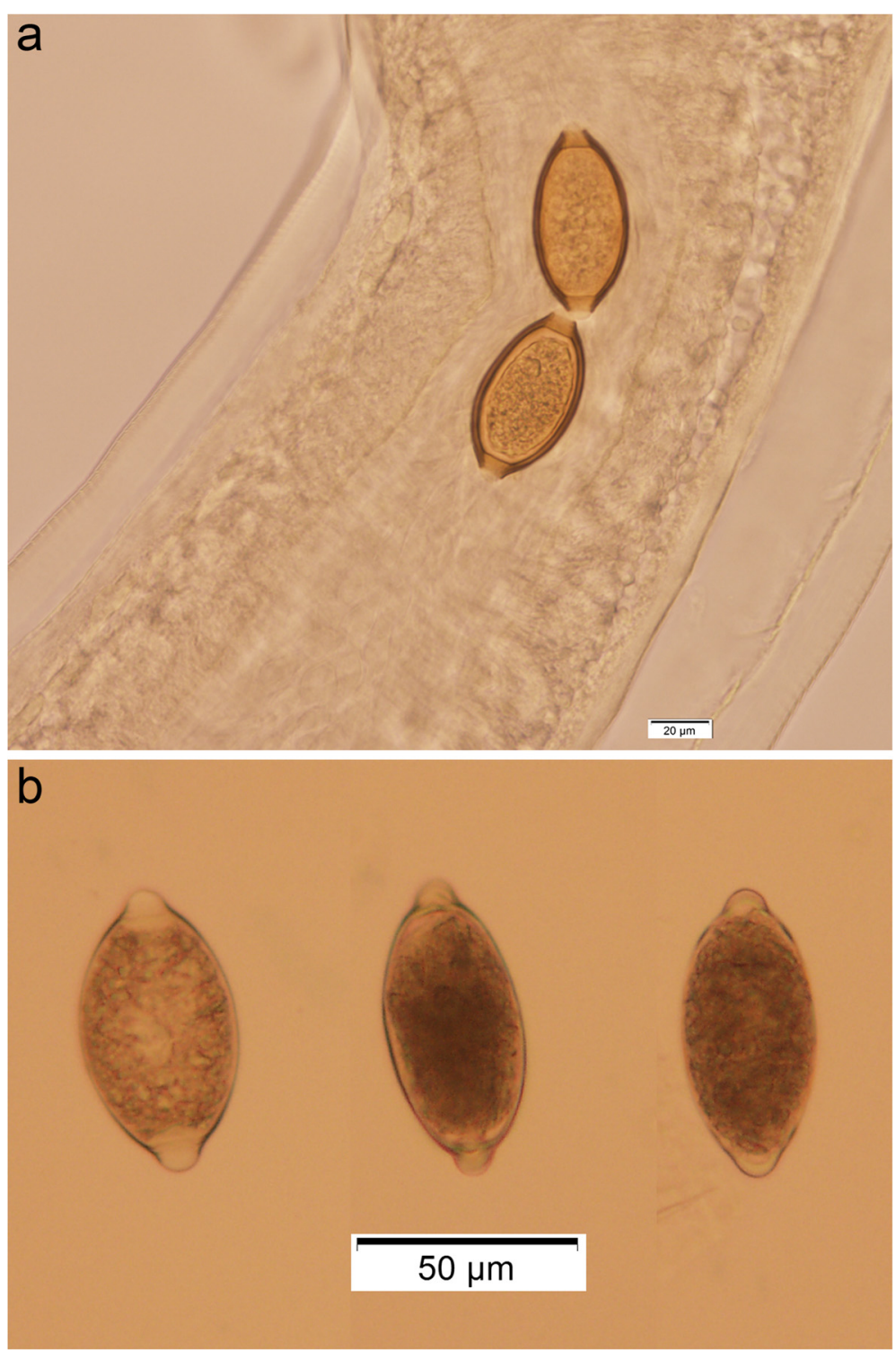

Figure 3 a and b Trichuris eggs (100x) of different sizes seen with a fecal flotation from one St. Kitts' cat.

If mislabeling occurred and only T. serrata has a projection, this does not address the issue of the size difference between Clarkson and Owen's specimens and those of other $T$. serrata specimens. While the $T$. serrata described by Cameron (1937) also was quite small and $\mathrm{Ng}$ and Kelly state that size is not definitive, these adult Trichuris are much smaller than the original description by von Linstow. Explanations for the size difference include: natural variation; a high larval exposure resulting in smaller adults; repeat infections in the host with host immunity decreasing adult worm size; and the number of adult worms present with population density regulating size (McKellar 1993; Stear et al. 1997; Walker et al. 2009; Luong et al. 2011). All of these effects have been seen in different gastro-intestinal species with variations in adult size being specifically noted with Trichuris muris and Trichuris suis (Michael and Bundy 1989; Kuchai et al. 2013). If these explanations are correct, they support $\mathrm{Ng}$ and Kelly's statement that the use of the existence or absence of the finger-like projection on the females is a better means of distinguishing the species versus using parasite size.

Frequently egg size is used for identification, especially in prevalence and treatment studies. However, the egg sizes overlap for the two species. Also, in other Trichuris species, it has been demonstrated that egg size can significantly vary between adult worms and within adult worms (Yoshikawa et al. 1989; Areekul et al. 2010). Hence, egg size does not appear to be a reliable determinant of species. 
Since neither of the species has been molecularly characterized, this method could not be used to identify the species on St. Kitts. Molecular characterization will be useful for differentiating the species when specimens matching the description of $T$. serrata and $T$. campanula are available.

\section{Conclusion}

After a review of the literature on the identification of Trichuris in cats, it is concluded that the species on St. Kitts is $T$. serrata. While the size more closely matches the $T$. campanula described by Clarkson and Owen (1960), it is hypothesized that the vulvar projection only occurs in T. serrata and parasite size is not a reliable criterion for distinguishing the species. To determine if the pathology associated with these infections on St. Kitts is species or strain related, morphological descriptions and molecular characterization of Trichuris from cats without pathologic changes are required; this might potentially impact the importance of treating Trichuris infections in cats world-wide.

\section{Methods}

The large intestine was collected from twelve cats euthanized due to health issues between February 2013 and March 2014. The large intestine was opened, soaked in saline at approximately $36^{\circ} \mathrm{C}$ for $1 \mathrm{~h}$ and then washed over a $50 \mu \mathrm{m}$ sieve to collect the adult Trichuris. All of the intact adults collected were examined for a bacillary band. All female adults were examined for a finger-like vulvar projection. One to four adult male (representing five cats) and one to four adult female worms (representing eleven cats) were morphologically examined in more detail: length of the male and female worms, length of the esophagus and length of the spicule were measured. The number selected was based primarily on the ability to separate whole undamaged worms. Lastly, eggs harvested from the female worms and eggs retrieved from the feces were measured from nine of the cats. An Olympus SZX16 with a microscope mounted camera (Olympus DP73) was used for photographing the parasites and these photographs with a stage micrometer were used for subsequent measuring of the parasites. Photographs of the vulvar projection, bacillary band and eggs were obtained using an Olympus BX41 with a microscope mounted camera (Olympus DP73). Eggs were measured using an ocular micrometer.

\section{Ethical standards}

All procedures in regards to the decision to euthanize the cats from which the Trichuris were harvested were approved by the Ross University School of Veterinary Medicine Institutional Animal Care and Use Committee.
All institutional and national guidelines for the care and use of laboratory and study animals were followed.

\section{Competing interests}

The author declares that she has no competing interests.

\section{Acknowledgements}

This study was funded by Ross University School of Veterinary Medicine. The author would like to thank Dr. Dwight Bowman with assistance in obtaining some obscure articles, Dr. Michael Dryden with assistance in interpretation of descriptions of Trichuris and Janel Cawthra for assistance with worm collection. All authors read and approved the final manuscript.

Received: 10 December 2014 Accepted: 17 February 2015

Published online: 05 March 2015

\section{References}

Areekul P, Putaporntip C, Pattanawong U, Sitthicharoenchai P, Jongwutiwes S (2010) Trichuris vulpis and T. trichiura infections among schoolchildren of a rural community in northwestern Thailand: the possible role of dogs in disease transmission. Asian Biomed 4:49-60

Beldomenico PM, Kinsella JM, Uhart MM, Gutierrez GL, Pereira J, Ferreyra HV, Marull CA (2005) Helminths of Geoffroy's cat, Oncifelis geoffroyi (Carnivora, Felidae) from the Monte desert, central Argentina. Acta Parasitol 50:263-266

Bowman DD, Hendrix CM, Lindsay DS, Barr SC (eds) (2002) Feline Clinical Parasitology. lowa State University Press, Ames, pp 348-350

Cameron TWM (1937) Studies on the endoparasitic fauna of Trinidad mammals. V. Further parasites from the Ocelot. Can J Res 15:24-27

Clarkson MJ, Owen LN (1959) The parasites of domestic animals in the Bahama Islands. Ann Trop Med Parasitol 53:341-346

Clarkson MJ, Owen LN (1960) The species of Trichuris in the domestic cat. J Helminthol 34:319-322

Hass DK, Meisels LS (1978) Trichuris campanula infection in a domestic cat from Miami, Florida. Am J Vet Res 39:1553-1555

Kelly JD (1973) Occurrence of Trichuris serrata von Linstow, 1879 (Nematoda: Trichuridae) in the domestic cat (felis catus) in Australia. J Parasitol 59:1145-1146

Ketzis JK, Shell L (2015) The prevalence of Trichuris spp. infection in indoor and outdoor cats on St. Kitts. J Infect Dev Ctries 9:111-113

Kirkova Z, Dinev I (2005) Morphological changes in the intestine of dogs, experimentally infected with Trichuris vulpis. Bulg J Vet Med 8:239-243

Krecek RC, Moura L, Lucas H, Kelly P (2010) Parasites of stray cats (Felis domesticus L., 1758) on St. Kitts, West Indies. Vet Parasitol 172:147-149

Kuchai JA, Ahmad F, Chishti MZ, Dar JA, Tak H (2013) On morphology and morphometry of Trichuris ovis Abildgaard, 1795 recovered from ruminants of Ladakh, India. J Buffalo Sci 2:49-52

Luong LT, Vigliotti BA, Hudson PJ (2011) Strong density-dependent competition and acquired immunity constrain parasite establishment: Implications for parasite aggregation. Int J Parasitol 41:505-511

McKellar QA (1993) Interactions of Ostertagia species with their bovine and ovine hosts. Int J Parasitol 23:451-462

Michael E, Bundy DAP (1989) Density dependence in establishment, growth and worm fecundity in intestinal helminthiasis: the population biology of Trichuris muris (Nematoda) infection in CBA/Ca mice. Parasitol 98:451-458

Ng BKY, Kelly JD (1975) Isolation of Trichuris campanula von Listow 1889 from Australian cats. Aust Vet J 51:450-451

Stear MJ, Bairden K, Duncan JL, Holmes PH, McKellar QA, Park M, Strain S, Murray M (1997) How hosts control worms. Nature 389:27

von Linstow OFB (1879) Helminthologische Untersuchungen. Jh Ver Vaterl Naturk Wurttemb 35:313-342

von Linstow OFB (1889) Helminthologisches. Arch Naturgesch 54:235-246

Walker M, Hall A, Anderson RM, Basáñez MG (2009) Density-dependent effects on the weight of female Ascaris lumbricoides infections of humans and its impact on patterns of egg production. Parasites Vectors 2:11-28

Yoshikawa H, Yamada M, Matsumoto Y, Yoshida Y (1989) Variations in egg size of Trichuris trichiura. Parasitol Res 75:649-654 